\title{
The New Disease of the Modern Age: What Is the Fear of Missing Out "FOMO"? A Review
}

\section{Modern Çağın Yeni Hastalığı: Gelişmeleri Kaçırma Korkusu “FOMO" Nedir? Bir Gözden Geçirme}

\author{
Ali Erdoğan ${ }^{1}$, Yavuz Yılmaz ${ }^{2}$, Çiçek Hocaoğlu
}

\begin{abstract}
:
Social networks have become a very important part of human life in recent years. This situation has led to new definitions such as the Fear of Missing Out (FOMO). FOMO can be defined as the concern that others can have a good experience when the person is absent and therefore the person wants to stay on social networks constantly to avoid missing anything. It is especially common in young people. Problematic internet use, psychosocial factors, social network use and anxiety are blamed in its etiology. Family conflicts, loneliness, depression, and low selfefficacy can be said as risk factors. People constantly want to spend time on social networks, daily life activities are blocked and the person's productivity decreases. It has no place in diagnostic classifications. For FOMO, the fear of missing out scale developed by Przybylski can be used. It is reported that FOMO has a significant positive relationship with nomophobia. There is no specific treatment method. There is a need for extensive research on FOMO.
\end{abstract}

Keywords: Fear of Missing Out, FOMO, Nomophobia, Smartphone, Internet

\footnotetext{
${ }^{1}$ Assist. Prof., University Faculty of Medicine, Department of Psychiatry, Antalya-Turkey, Orcid İd: https://orcid.org/00000003-0329-6778

${ }^{2}$ MD., Gümüşhane State Hospital, Gümüşhane-Turkey, Orcid İd: https://orcid.org/0000-0002-7572-5474

${ }^{3}$ Prof. Dr., Recep Tayyip Erdogan University Faculty of Medicine, Department of Psychiatry, Rize-Turkey, Orcid İd: https://orcid.org/0000-0001-6613-4317
}

Date of Received/Geliş Tarihi: 23.02.2021, Date of Revision/Düzeltme Tarihi: 01.04.2021, Date of Acceptance/Kabul Tarihi: 04.08.2021, Date of Online Publication/Çevirimiçi Yayın Tarihi: 01.09.2021

Citing/Referans Gösterimi: Erdoğan, A., Yılmaz, Y., Hocaoğlu, Ç. (2021). The New Disease of the Modern Age: What is the Fear of Missing Out “FOMO”? A review, Cyprus Turkish Journal of Psychiatry \& Psychology, 3(3): 217-222.

(C) 2021 The Author(s). Published by Cyprus Mental Health Institute / Cyprus Turkish Journal of Psychiatry and Psychology (www.ktppdergisi.com). This article is an open access article distributed under the terms and conditions of the Creative Commons Attribution 4.0 license which permits use, sharing, adaptation, distribution and reproduction in any medium or format, provided the original work is properly cited and is not used for commercial purposes. http://creativecommons.org/licenses/by/4.0/

Erdoğan, A., Yllmaz, Y. \& Hocaoğlu, Ç. (2021). 


\section{Öz:}

Son yıllarda sosyal ağlar insan hayatının çok önemli bir parçası haline gelmiştir. Bu durum Gelişmeleri Kaçırma Korkusu (FOMO - Fear Of Missing Out) gibi yeni tanımlamalara neden olmuştur. FOMO, başkalarının kendisi yokken güzel bir deneyim yaşayabileceği endişesi ve bu sebeple kişinin bir şey kaçırmamak için sürekli sosyal ağlarda kalmak istemesi olarak tanımlanabilir. Özellikle gençlerde sıktır. Etiyolojisinde problemli internet kullanımı, psikososyal faktörler, sosyal ağ kullanımı ve anksiyete suçlanmaktadır. Aile içi çatışmalar, yalnızlık, depresyon, düşük öz-yeterlilik risk faktörleri olarak söylenebilir. Kişiler sürekli sosyal ağlarda vakit geçirmek ister, günlük yaşam aktiviteleri engellenir ve kişinin verimliliği düşer. Tanı sınıflandırmalarında yeri yoktur. FOMO için Przybylski tarafından geliştirilen Gelişmeleri Kaçırma Korkusu Ölçeği (GKKÖ) kullanılabilir. FOMO’nun nomofobi ile pozitif yönde anlamlı ilişkisi olduğu bildirilmektedir. Özgün bir tedavi yöntemi yoktur. FOMO konusunda geniş çaplı araştırmalara ihtiyaç vardır.

Anahtar Kelimler: Gelişmeleri Kaçırma Korkusu, FOMO, Nomofobi, Akıllı Telefon, İnternet

\section{Giriş}

İnsanlar belli bir gruba dahil olma eğilimindedirler. Günümüzde bu durum sadece fiziksel olarak değil, sanal olarak da kendini göstermektedir. Grup üyelerinin belirli bir zaman diliminde birbirlerinin ne yaptıklarını anlama ihtiyac1 vardır (Abel, Buff ve Burr 2016, s. 33-44). Sosyolojik olarak normal kabul edilen bu durum, bazen ödüllendirici deneyimleri kaçırma korkusu ve kișinin sosyal ağıyla sürekli bağlantıda kalma ihtiyacı şeklinde bir soruna dönüşebilir. Son zamanlarda literatürde kendine yer bulan Gelişmeleri Kaçırma Korkusu (FOMO) İngilizce "Fear Of Missing Out" kelimelerinin baş harflerinden oluşturulmuştur ve ilk kez Przybylski tarafından tanımlanmıştır. FOMO, kişinin bulunmadığı ortamlarda başkalarının ödüllendirici deneyimler yaşıyor olabileceğine dair yaygın bir endişe olarak tanımlanmıştır (Przybylski, Murayama, DeHaan ve Gladwell 2013, s. 1841-1848). Bu makalede güncel literatür 1şı̆̆ında FOMO'nun gözden geçirilmesi amaçlanmıştır.

\section{Yöntem}

$\mathrm{Bu}$ çalışma geleneksel derleme olacak şekilde yazılmıştır. Çalışma, konuyla ilgili Türkiye'de ve dünyada yapılmış olan çalışmaların taranması biçiminde gerçekleştirilmiştir. Fear of Missing Out ve Gelişmeleri Kaçırma Korkusu anahtar kelimeleriyle PubMed, Dergipark, Google Akademik ve Yök Tez sayfalarında taramalar yapılmıştır.

\section{Epidemiyoloji}

Dijital teknoloji ve sosyal medya, dünyanın her yerinde insanlar için günlük yaşamın vazgeçilmez bir parçası haline gelmiştir. 2020 y1lında 4,5 milyardan fazla insan internet kullanırken, sosyal medya kullanıcılarının sayısı 3,8 milyarı aşmıştır (We are social, 2020) Hanehalkı bilişim teknolojileri kullanım araştırması 2020 sonuçlarına göre ülkemizde internet kullanan 16-74 yaş grubundaki bireylerin oran $1 \% 79,0$ olmuştur. $\mathrm{Bu}$ oran erkeklerde $\% 84,7$ ve kadınlarda \%73,3 olarak bildirilmiştir. Evden internete erişim imkânı \%90,7 olmuştur (TUIK, 2020). Görüldüğü gibi ülkemizde ve dünyada internet kullanımı son derece yüksekken, FOMO ile ilgili epidemiyolojik araștırma sayısı kısıtlıdır. Przybylski'ye göre FOMO, sosyal ağların kullanımdaki artıșa sebep olan ana etkendir. FOMO düzeyleri gençlerde ve özellikle genç erkeklerde daha yüksek bildirilmiştir (Przybylski ve ark., 2013). Ülkemizde 210 üniversite öğrencisi ile yapılan bir çalışmada FOMO'nun yaygınlığ 1 araştırılmıştır. FOMO ölçeğine ait tanımlayıcı bilgiler incelendiğinde; katılımcıların genel ölçek ortalamasının 2,86 olduğu ve soruların yarısına ait ortalamanın, genel ölçek ortalamasından daha yüksek olduğu tespit edilmiştir. Çalışmada üniversite öğrencilerinde FOMO yaygınlığının orta düzeyde olduğu tespit edilmiştir. FOMO düzeyinin kadın ve erkeklerde benzer olduğu saptanmıştır. Ögrenciler tarafindan en fazla kullanılan uygulamalar sirasiyla WhatsApp, Instagram, Facebook, Youtube, Snapchat, Twitter, Swarm, Pinterest, Tumblr, LinkedIn ve Periscope olarak bulunmuştur (Hoşgör, Koç Tütüncü, Gündüz Hoşgör ve Tandoğan 2017, p. 213-223). 200 üniversite öğrencisi ile yapılan başka bir çalışmada ise ögrencilerin en fazla kullandığı uygulamalar sirasiyla Facebook, WhatsApp, Instagram ve Twitter olarak saptanmıştır (Gökler, Aydın, Ünal, E ve Metintaş 2016, s. 52-59). 400 üniversite öğrencisi ile yapılan başka bir çalışmada, katılımcıların \%16,5'inin internet bağımlısı olduğu tespit edilmiştir. En çok tercih edilen uygulamalar sirasiyla, Instagram (\%84), Facebook (\%81) ve Snapchat $(\% 56,75)$ olarak saptanmıştır. İnternet bağımlılı̆̆ı ile FOMO arasında pozitif yönlü bir ilişki bulunmuştur (Çınar ve Mutlu, 2019, s. 133-142)

FOMO hakkında epidemiyolojik araştırmalar çok kısıtlı olup, geniş çaplı epidemiyolojik araştırmalara ihtiyaç olduğu görülmektedir.

\section{Etiyoloji}

FOMO etiyolojisi net olmamakla birlikte, etiyolojide farklı faktörler suçlanmaktadır. FOMO, bir bireyin motivasyonlarının, davranıșlarının ve refahının doğuştan gelen özerklik, yeterlilik ve ilgili olma gibi üç psikolojik ihtiyaçla bağlantılı olduğunu öne süren kendi kaderini tayin teorisi ile ilişkilendirilebilir. Bir bireyin ihtiyaçlarını karşılama girişimleri engellendiğinde, uyumsuz psikososyal sonuçlar ürettiği gösterilmiştir (Véronneau, Koestner ve Abela 2005, s. 280-292). FOMO etiyolojisinde problemli internet kullanımı özellikle 
suçlanmaktadır. FOMO'nun sorunlu dijital teknoloji kullanımıyla tutarlı bir şekilde ilişkili olduğu gösterilmiştir (Wolniewicz, Rozgonjuk ve Elhai 2020, s. 61-70). 538 üniversite öğrencisinde yapılan bir çalışmada, FOMO'nun problemli internet kullanımının alt boyutlarının tamamı ile anlamlı ve pozitif yönde ilişkisinin olduğu bildirilmiştir. Çalışma sonucunda FOMO'nun problemli internet kullanımının bir alt boyutu olarak düşünülebileceği bildirilmiştir (Göksun, 2019).

1097 katılımcıdan oluşan bir çalışmada, FOMO en çok problemli akıllı telefon kullanımı şiddeti ile ilişkili bulunmuştur (Elhai, Yang, Rozgonjuk ve Montag 2020). 316 Amerikan üniversite öğrencisi ile yapılan bir çalışmada, sosyal olarak akıllı telefon kullanımına kıyasla, sosyal olmayan kullanımın problemli akı1lı telefon kullanımı ve FOMO'nun şiddeti ile güçlü bir şekilde bağlantılı olduğu bildirilmiştir. FOMO, depresyon şiddeti ile sosyal olmayan akıllı telefon kullanımı arasındaki ilişkilere aracılık etmiştir (Elhai, Gallinari, Rozgonjuk ve Yang 2020).

Sosyal içeriğe erişim de FOMO’ya neden olmaktadır. Bireyler Facebook arkadaşlarının profillerini, davranışlarını ve sosyal ilişkilerini izleyerek sorunlu sosyal karşılaştırmalar yapabilir. Sik sık yapılan sosyal karşlaştırmalar, FOMO duyguları üretme kapasitesine sahiptir. Kişiler kendilerini sosyal olarak aşağılık hissedebilir ve sosyal ağları tarafından dışlanma riski altında algılayabilir. Sonuç olarak bireyler, çevrimiçi olarak artan kendini ifșa etme davranıșlarında bulunabilir (Gilbert, McEwan, Bellew, Mills ve Gale 2009, s. 123136; Lee ve Cho, 2018, s. 32-39). Sosyal ağ sitelerinin kullanımı FOMO ile ilişkilendirilmiştir. Facebook kullanıcılarından oluşan 190 kişi ile yapılan bir çalışmada, daha yüksek FOMO seviyelerinin, aşağılık hissetmekten kaçınma arzusunun artmasıyla ilişkili olduğu gösterilmiştir. $\mathrm{Bu}$ durum da daha yüksek seviyelerde kişilerarası manipülasyon ve daha yüksek Facebook ilişkili saldırganlık oranları ile ilişskilendirilmiştir (Abell, Buglass ve Betts 2019, s. 799-803)

Anksiyetenin FOMO etiyolojisinde yeri olduğu bildirilmiştir. 14-18 yaş arasındaki 517 öğrencide FOMO ile depresyon ve anksiyete düzeyi arasında pozitif yönde orta düzeyde anlamlı bir ilișkinin olduğu bulunmuștur. Anksiyetenin FOMO davranışının \%22'sini açıkladı̆̆ı ancak depresyonun FOMO davranışını yordamadığ 1 görülmüştür. FOMO davranışı ile mutluluk arasında anlamlı bir ilişki saptanmamıştır. FOMO davranışının kız öğrencilerde daha yüksek olduğu saptanmıştır (Kartol ve Peker, 2020, s. 454-474).

\section{Risk Faktörleri}

Düşük ifade gücü, düşük uyum ve yoğun çatışmalar ile karakterize edilen bir aile ortamı, genellikle ergenler arasında problemli internet kullanımı ile ilişkilendirilmektedir. 12-16 yaş arası 85 ergen ve ebeveynleri ile yapılan bir çalışmada, düşük aile ifadesinin ve yüksek aile içi çatı̧̧maların, depresyon ve FOMO aracılığ 1 ile çevrimiçi olarak harcanan süreyi etkilediği gösterilmiştir. Sonuçlar, pozitif aile ortamının ergenler arasinda depresif semptomları ve FoMO'yu azaltabileceğini ve dolayısıyla internette harcanan zamanı azaltabileceğini göstermiştir (Sela, Zach, AmichayHamburger, Mishali ve Omer 2020).
14-39 yaş arasındaki Alman internet kullanıcılarında yapılan bir çalışmada yalnızlık, depresyon ve anksiyetenin sosyal medya katılımını arttırdığı, FoMO ve sosyal karşılaştırma yapma eğiliminin, iyi hissetme ve sosyal medya katılımı arasındaki bağlantıya aracılık ettiği bildirilmiştir. Yani iyi hissetmedeki düşüşler FOMO ve sosyal medya katılımındaki artışlarla bağlantılıdır. Ayrıca, başkalarıyla sosyal durumlarını karşıllaştırma eğilimi yüksek olanların FOMO gelişiminde bir risk grubu olabileceği bildirilmiştir (Reer, Tang ve Quandt 2019, s. 1486-1505)

Ülkemizde 346 üniversite öğrencisi ile yapılan bir çalışmada öz-yeterlilik ile FOMO arasında ters bir ilişki bildirilmiştir. Öz yeterlilik seviyesi yüksek olan öğrencilerin daha düşük düzeyde FOMO riski olduğu söylenebilir (Erdoğan ve Şanlı, 2019, s. 594-620). FoMO ile nevrotik kişilik özellikleri arasında ilişki olduğu bildirilmiştir (Alt ve Boniel-Nissim, 2018, s. 1264-1276). Yine çok fazla sosyal medya kullanmanın olumsuz sonuçlarından birisi FOMO davranışıdır (Rozgonjuk, Sindermann, Elhai ve Montag 2020).

\section{Tanı ve Klinik Görünümü}

FOMO, doğuştan gelen psikososyal ihtiyaçlarda algılanan eksikliklere neden olabilir. Bu ihtiyaçları düzenleme girişimleri, artan sosyal ă̆ katılımı, çevrimiçi öz sunumda artış ve abartılı arkadaşlık davranışları gibi telafi edici çevrimiçi davranışlarla ilişkilendirilmiştir. Ayrıca, yüksek FOMO seviyeleri sergileyen bireyler, Facebook ile ilgili artan stres, Facebook saldırısı ve yaşam memnuniyetinde azalma gibi çeşitli olumsuz sonuçlar bildirmişlerdir (Błachnio ve Przepiórka, 2018; Beyens, Frison ve Eggermont 2016, s. 1-8). Sosyal ağlarda arkadaşlarının güncellemelerini izlememek FOMO'ya sahip olan bireyleri ciddi şekilde rahatsız eder. FOMO'ya sahip olan bireyler sosyal ağlarda geçirdikleri süre dışındaki yaşamlarında sürekli yalnız hissettiklerini bildirmekte, normal yaşamdaki ilişkilerinde eksik olan sevgi ve şefkati bilgi paylaşma ve yayılmasını sağlama ile tamamlamaya çalışmaktadırlar (Dossey, 2014). FOMO'nun önemli bir sonucu sosyal medyada daha çok zaman harcanmasına neden olmasidır (Abel ve ark., 2016). FOMO'ya daha yatkın öğrencilerin yanlarında sürekli şarj cihazı taşıdığı, sabah uyanınca akıllı telefonlarını kontrol ettiği, yatağa akı1lı telefonla girdiği, her gün sosyal medyaya bağlandığı, akıllı telefonlarını günlük en az $50 \mathrm{kez}$ kontrol ettiği, en az 7 yıldır bir sosyal medya hesabına sahip olduğu, en az 4 farklı sosyal medya hesabının olduğu ve günde en az 7 saatini sosyal medyada geçirdiği saptanmıştır (Hoşgör ve ark., 2017).

Daha yüksek FOMO seviyeleri, akıllı telefon bildirimleri nedeniyle üniversite öğrencileri arasında ders çalışmak gibi aktivitelerde daha yüzeysel bir yaklaşıma yol açabilir. FOMO ara ara bildirimler almaktan kaynaklanan kesintiye uğramış günlük faaliyetlerle ilişkilendirilmektedir (Rozgonjuk, Elhai, Ryan ve Scott 2019). 93 üniversite öğrencisinde yapılan bir çalışmada, yüksek FOMO düzeyleri bütün bir hafta boyunca olumsuz etkilerle ilişkili bildirilmiştir (Elhai, Rozgonjuk, Liu ve Yang 2020, s. 298303). Daha yüksek düzeyde FOMO'ya sahip bireyler anlık bildirimlere tepki vermeye daha yatkındırlar. $\mathrm{Bu}$ nedenle bu kişilerin üretkenliği ciddi anlamda engellenebilir çünkü kişi sürekli bilirimler ile meşguldür (Rozgonjuk ve ark., 2018). Daha fazla FOMO'ya sahip kişilerin bildirimlere karşı daha tetikte olabileceği ve 
dikkati sürekli meşgul olduğu için daha zayıf konsantrasyona sahip olacağı varsayılmıştır (Duke ve Montag, 2017, s. 90-95). FOMO araç kullanımı sırasında dikkat dağınıklığı gibi günlük yaşam aksaklıklarıyla ilişkilendirilmiştir. FOMO ayrıca sürekli olarak internet, akıllı telefon ve sosyal ağ kullanım bozukluklarının bir öngörücüsü olmuştur. 748 kişiyle yapılan bir çalışma, tüm sosyal ağ kullanım bozukluklarının şiddetinin, FOMO ve sosyal medyanın günlük yaşam ve işyerindeki verimlilik üzerindeki olumsuz etkisi ile pozitif yönde ilişkili olduğunu göstermiştir (Rozgonjuk ve ark., 2020).

Öğrencilerde FOMO özellikle günün ilerleyen saatlerinde, haftanın ilerleyen günlerinde ve ders çalışmak gibi gerekli bir görevi yaparken sık sık deneyimlenmektedir. Daha sık FOMO deneyimleri, yorgunluk, stres, fiziksel semptomlar ve azalmış uyku gibi olumsuz sonuçlarla ilişkilendirilmiştir (Milyavskaya, Saffran, Hope, N ve Koestner 2018, s. 725-737).

FOMO'nun bir diğer olumsuz sonucu; kişilerin kendileri hakkında daha olumlu bir değerlendirme yaratmak amacıyla, başkalarının statüsünü azaltmak için kişiler arası manipülasyon gibi davranışlara yönelebilmesidir. $\mathrm{Bu}$ sosyal manipülasyonu kullanma eğilimi daha sonra çevrimiçi ilişkisel saldırganlıkla ilişkili olabilir (Asher, Stark ve Fireman 2017, s. 26-34; Leary, Twenge ve Quinlivan 2006, s. 111-132).

Bir çalışmada, 11-19 yaş arasındaki 472 İtalyan öğrencide FOMO, ergenlerde duygusal iyilik halindeki azalma ile ilişkili bildirilmiştir. FOMO düzeyi yüksek ergenler, çevrimiçi akranlarının ihmalinden kaynaklanan artan stres yaşamaktadırlar. Akran ihmaline bağlı stresin sosyal medya bağımlılı̆̆ını yordadığı bulunmuştur (Fabris, Marengo, Longobardi ve Settanni 2020).

FOMO, tüketimi arttırmaya yönelik pazarlama ve iletişim faaliyetlerinde de dürtüsel bir araç olarak kullanılabilir (Aydin, Selvi, Kandeger ve Boysan 2019, s. 1-9). Çin'de 1127 üniversite öğrencisinde yapılan çalışmada, yüksek FOMO seviyelerine sahip bireylerin dürtüsellik düzeylerinin ve internette oyun oynama sürelerinin daha uzun olduğu bildirilmiştir ( $\mathrm{Li}$, Griffiths, Niu, $\mathrm{Z}$ ve Mei 2020, s. 1104-1113). Başka bir çalışmada da FOMO'nun daha yüksek alkol tüketimi ve alkole bağlı olumsuz davranışlarla ilişsili olduğu bulunmuştur (Riordan, Flett, Hunter, Scarf ve Conner 2015, s. 1-7).

Tanı için belirlenmiş kriterleri yoktur. Mental Bozuklukların Tanısal ve Sayımsal El Kitabı 5 (DSM-5) ve Hastalıkların Uluslararası Sınıflaması 11 (ICD-11) gibi tanı sinıflandırmalarında yeri yoktur (ICD-11, 2020; American Psychiatric Association, 2013). FOMO taramas1 için çeşitli ölçekler vardır. Gelişmeleri kaçırma korkusu ölçeği (GKKÖ) Przybylski tarafindan geliştirilen, 10 sorudan oluşan beşli likert tipi bir ölçektir. Ölçek kişilerin kendi yaşamlarıyla ilgili değerlendirmelerini içermektedir. Ölçekte yer alan her madde $1-5$ puan $(1=$ hiç doğru değildir, 5=aşırı şekilde doğrudur) arasında puanlandırılmaktadır. Kişilerin ölçekten aldıkları puan 1050 arasında değişmekte olup, ölçeğin kesme puanı yoktur. Ölçekten alınan puan arttıkça bireyin FOMO olma olasılığı artmaktadır (Przybylski ve ark., 2013). GKKÖ Türkçe versiyonunun geçerlilik ve güvenilirliği 2016 yılında Gökler ve arkadaşları tarafindan yapılmıştır (Gökler ve ark., 2016). Üsküdar Gelişmeleri Kaçırma Korkusu Ölçeği (ÜGKK) ülkemizde oluşturulmuş FOMO taramasında kullanılabilecek bir başka ölçektir. Orijinal olarak 31 maddeyle hazırlanan ölçeğin yapılan analizler sonrası 22 maddesi son haline dâhil edilmiştir. Ölçeğin geçerlilik ve güvenilirliği yeterli düzeyde bulunmuştur. Ölçek 5'li likert tarzında hazırlanmış ve katılımcılardan her maddeye ne kadar katıldıklarını belirtmeleri istenmiştir (Geçerlilik, 2017)

\section{Netless ve Nomofobi İle İlişkisi}

İngilizce "Being Netless Phobia" yani internetsiz kalma korkusu olarak nitelendirilen netless kavramı, aşırı internet kullanımı değildir. Kişinin internetin olmadığı bir ortamda kalamaması ve internet yoksunluğundan endişe duyması olarak tanımlanmaktadır. İnternetsiz kalma korkusu yaşayan bireylerde, internet bağımlılı̆̆ 1 ve diğer bağımlılık durumlarına benzer gerginlikler, sinirlilik ve öfkelenme gibi yoksunluk belirtileri görülebilir (Yıldız ve Yıldız, s. 108-115). Nomofobi ise cep telefonunun, kişisel bilgisayarın veya başka bir sanal iletişim cihazının bulunmamasından kaynaklanan aşırı endişe hali olarak tanımlanmaktadır (King ve ark., 2013). Nomofobi, İngilizce "no mobile phobia" kelimlerinin kısaltmasıdır ve dilimizde cep telefonsuz kalma fobisi şeklinde ifade edilebilir (King, Valença ve Nardi 2010, s. 52-54).

548 öğrencide yapılan bir çalışmada, FOMO, nomofobi ve internet bağımlılığı alt boyutları arasında orta düzeyde pozitif yönde bir ilişki tespit edilmiştir. Ayrıca FOMO ve nomofobinin internet bağımlığının önemli bir yordayıcısı olduğu saptanmıştır (Yıldız, Kurnaz ve Kırık 2020, s. 321338). 685 öğretmenle yapılan başka bir çalışmada, nomofobi ve FOMO arasında pozitif yönde doğrusal bir ilişski olduğu saptanmıştır (Arslan, Tozkoparan ve Kurt 2019, s. 237-256). Gezgin ve ark. yaptığ 1 çalışmada 538 üniversite öğrencisinde nomofobi ve FOMO düzeyleri arasında pozitif yönde orta düzeyde bir ilişki bulunmuştur (Gezgin, Hamutoglu, Sezen-Gultekin ve Gemikonakli 2018, s. 549-561).

273 öğrenciden oluşan bir çalışmada, öğrencilerin nomofobi ve FOMO düzeylerinin ortalamanın üzerinde olduğu bildirilmiştir. Nomofobi ve FOMO arasında orta düzeyde anlamlı bir ilişki olduğu ve FOMO'nun nomofobinin \%30'unu açıkladığını gösterilmiştir. Ayrıca sonuçlar, öğrencilerin nomofobi ve FOMO düzeyleri ile demografik özellikleri arasında istatistiksel olarak anlamlı farklılıklar olduğunu göstermiştir (Hoşgör ve Hoşgör, 2019, s. 16-24). 178 hemşire ile yapılan bir çalışmada nomofobi, FOMO ve algılanan iş yükü değişkenleri arasında pozitif ve anlamlı bir ilişki saptanmıştır. Nomofobi ve FOMO bağımsız değişkenleri, algılanan iş yükünün \% 6'sını açıklamıştır (Hoşgör, Coşkun ve Çalişkan 2020). Daha yüksek FOMO seviyeleri ve mobil bağlanma, daha yüksek seviyelerde nomofobiye yol açmaktadır (Gezgin ve ark., 2018)._Görüldüğü gibi, sosyal olayları kaçırma korkusu, kişinin akı1lı telefonu olmadan kalma korkusunu geliştirmede önemli bir faktör olabilir.

\section{Tedavi Yaklaşımları}

Özgün tanımlanmış bir tedavi yöntemi yoktur. İnternet bağımlılı̆̆ı olan kişilerde bilişsel davranışçı müdahalelerin etkin olduğu daha önce tanımlanmıştır (Young, 2011). İnternet bağımlılı̆gı ve FOMO arasındaki yakın ilişki düşünüldüğünde, FOMO tedavisi için de bilişsel davranışçı müdahaleleri önerebiliriz. Farkındalık temelli müdahalelerin de sorunlu internet kullanımının gelişiminde koruyucu bir faktör olarak hizmet edebileceği gösterilmiştir. Artan öz farkındalık, duygu ve düşüncelerin 
tanımlanması ve kabul edilmesi gibi temel farkındalık mekanizmalarının vurgulanması, sorunlu internet kullanımı ve internet bağımlılığının önlenmesine ve tedavisine önemli ölçüde katkıda bulunabilmektedir (Gámez-Guadix ve Calvete, 2016). Yine internet bağımlılığı için erken uyumsuz şemaların rolü olduğu bildirilmektedir (Ostovar, Bagheri, Griffiths ve Mohd Hashima 2021). Bu literatürler ışığında farkındalık temelli terapilerin ve şema terapinin FOMO tedavisinde etkili olabileceğini düşünüyoruz.

\section{Sonuç ve Öneriler}

Dijital teknoloji, internet ve sosyal medya kullanımının hayatımızın artık vazgeçilmez bir parçası olduğu düşünüldüğünde, FOMO'nun önümüzdeki süreçte psikiyatri pratiğinde çok fazla yer bulacağını söyleyebiliriz. Ancak şu ana kadar literatürde sınırlı sayıda araştırma bulunmaktadır. Bu araştırmalar da sınırlı sayıda katılımcı ile yapılmıştır. Toplum temelli epidemiyolojik çalışmalar son derece kısıtlıdır. Klinisyenlerin bu durumu tanıması ve uygun müdahale yöntemlerini bilmesi önemlidir. $\mathrm{Bu}$ konudaki araştırmaların kısıtlı olduğu düşünüldüğünde, özellikle tedavi yaklaşımlarını içerecek geniş örneklemli plasebo kontrollü çalışmalara ihtiyaç olduğunu söyleyebiliriz.

\section{Beyannameler}

Etik Onayı ve Katılım Onayı

Uygulanamaz.

Yayın İzni

Uygulanamaz.

Veri ve Materyallerin Mevcudiyeti

Mevcut çalışma sırasında herhangi bir veri kümesi oluşturulmadığı veya analiz edilmediğinden veri paylaşımı bu makale için geçerli değildir.

\section{Çıkar çatıșması}

Yazarlar çıkar çatışması olmadığını beyan eder.

\section{Finansman}

Uygulanamaz.

\section{Yazar Katkıları}

Tüm yazarlar makalenin yazılmasında eşit derecede katkı sağlamıştır. Tüm yazarlar makalenin son halini okumuş ve onaylamıştır.

\section{Teșekkürler}

Uygulanamaz.

\section{Kaynaklar}

Abel, J. P., Buff, C. L., \& Burr, S. A. (2016). Social media and the fear of missing out: Scale development and assessment. Journal of Business \& Economics Research (JBER), 14(1), 33-44.

Abell, L., Buglass, S. L., \& Betts, L. R. (2019). Fear of missing out and relational aggression on Facebook. Cyberpsychology, Behavior, and Social Networking, 22(12), 799-803. doi: 10.1089/cyber.2019.0071. Epub 2019 Oct 29. PMID: 31657626.

Alt, D., \& Boniel-Nissim, M. (2018). Using multidimensional scaling and PLS-SEM to assess the relationships between personality traits, problematic internet use, and fear of missing out. Behaviour \& Information Technology, 37(12), 1264-1276.

American Psychiatric Association. (2013). Diagnostic and statistical manual of mental disorders (5th ed.). Arlington, VA: Author.

Arslan, H., Tozkoparan, S. B., \& Kurt, A. A. (2019). Öğretmenlerde Mobil Telefon Yoksunluğu Korkusunun ve Gelişmeleri Kaçırma Korkusunun İncelenmesi. Erzincan Üniversitesi Eğitim Fakültesi Dergisi, 21(3), 237-256.

Asher, Y., Stark, A., \& Fireman, G. D. (2017). Comparing electronic and traditional bullying in embarrassment and exclusion scenarios. Computers in Human Behavior, 76, 26-34.

Aydin, D., Selvi, Y., Kandeger, A., \& Boysan, M. (2019). The relationship of consumers' compulsive buying behavior with biological rhythm, impulsivity, and fear of missing out. Biological Rhythm Research, 1-9. https://doi.org/10.1080/09291016.2019.1654203.

Beyens, I., Frison, E., \& Eggermont, S. (2016). "I don't want to miss a thing": Adolescents' fear of missing out and its relationship to adolescents' social needs, Facebook use, and Facebook related stress. Computers in Human Behavior, 64, 1-8.

Błachnio, A., \& Przepiórka, A. (2018). Facebook intrusion, fear of missing out, narcissism, and life satisfaction: A cross-sectional study. Psychiatry research, 259, 514-519. doi: 10.1016/j.psychres.2017.11.012. Epub 2017 Nov 7. PMID: 29154204.
Çınar, Ç. Y., \& Mutlu, E. (2019). İnternet bağımlılı̆ı̆ın benlik saygısı, dikkat, gelişmeleri kaçırma korkusu, yaşam doyumu ve kişilik özellikleri ile ilişkisi. Bağımlllık Dergisi, 20(3), 133-142.

Dossey, L. (2014). FOMO, digital dementia, and our dangerous experiment. Explore: The Journal of Science and Healing, 10(2), 69-73.

Duke, É., \& Montag, C. (2017). Smartphone addiction, daily interruptions and self-reported productivity. Addictive behaviors reports, 6, 90-95.

Elhai, J. D., Gallinari, E. F., Rozgonjuk, D., \& Yang, H. (2020). Depression, anxiety and fear of missing out as correlates of social, non-social and problematic smartphone use. Addictive behaviors, 105, 106335. doi: 10.1016/j.addbeh.2020.106335. Epub 2020 Feb 7. PMID: 32062337.

Elhai, J. D., Rozgonjuk, D., Liu, T., \& Yang, H. (2020). Fear of missing out predicts repeated measurements of greater negative affect using experience sampling methodology. Journal of affective disorders, 262, 298-303. doi: 10.1016/j.jad.2019.11.026. Epub 2019 Nov 9. PMID: 31733919.

Elhai, J. D., Yang, H., Rozgonjuk, D., \& Montag, C. (2020). Using machine learning to model problematic smartphone use severity: The significant role of fear of missing out. Addictive behaviors, 103, 106261. doi: 10.1016/j.addbeh.2019.106261. Epub 2019 Dec 28. PMID: 31901886.

Erdoğan, P., \& Sanlı, Y. (2019). Sağlık bilimleri fakültesi öğrencilerinde genel özyeterliliğin gelişmeleri kaçırma korkusu üzerine etkisi. OPUS Uluslararası Toplum Araştırmaları Dergisi, 14(20), 594-620.

Fabris, M. A., Marengo, D., Longobardi, C., \& Settanni, M. (2020). Investigating the links between fear of missing out, social media addiction, and emotional symptoms in adolescence: The role of stress associated with neglect and negative reactions on social media. Addictive Behaviors, 106, 106364. doi: 10.1016/j.addbeh.2020.106364. Epub 2020 Feb 27. PMID: 32145495 .

Gámez-Guadix, M., \& Calvete, E. (2016). Assessing the relationship between mindful awareness and problematic Internet use among adolescents. Mindfulness, 7(6), 1281-1288. 
Geçerlilik, Ü. G. K. K. Ö. (2017). Realiability and validity of Uskudar fear of missing out scale. JNBS, 43.

Gezgin, D. M., Hamutoglu, N. B., Sezen-Gultekin, G., \& Gemikonakli, O. (2018). Relationship between Nomophobia and Fear of Missing out among Turkish University Students. Cypriot Journal of Educational Sciences, 13(4), 549-561.

Gilbert, P., McEwan, K., Bellew, R., Mills, A., \& Gale, C. (2009). The dark side of competition: How competitive behaviour and striving to avoid inferiority are linked to depression, anxiety, stress and self- harm. Psychology and Psychotherapy: Theory, Research and Practice, 82(2), 123-136. doi: 10.1348/147608308X379806. Epub 2008 Nov 26. PMID: 19040794 .

Gökler, M. E., Aydın, R., Ünal, E., \& Metintaş, S. (2016). Sosyal ortamlarda gelişmeleri kaçırma korkusu ölçeğinin Türkçe sürümünün geçerlilik ve güvenilirliğinin değerlendirilmesi. Anadolu Psikiyatri Dergisi, 17(1), 52-59.

Hoşgör, H., Coşkun, F., \& Çalişkan, F. (2020). Relationship between nomophobia, fear of missing out, and perceived work overload in nurses in Turkey. Perspectives in Psychiatric Care. https://doi.org/10.1111/ppc.12653.

Hoşgör, H., Koç Tütüncü, S., Gündüz Hoşgör, D., \& Tandoğan, Ö. (2017). Üniversite öğrencileri arasında sosyal medyadaki gelişmeleri kaçırma korkusu yaygınlığının farklı değişkenler açısından incelenmesi. International Journal of Academic Value Studies, 3(17), 213-223.

Hoşgör, H., \& Hoşgör, G. D. (2019). The relationship among nomophobia, fear of missing out and demographic variables: example of the healthcare manager candidates. Curr Addict Res, 3(1), 16-24.

https://data.tuik.gov.tr/Bulten/Index?p=Hanehalki-BilisimTeknolojileri-(BT)-Kullanim Arastirmasi-2020-33679

https://icd.who.int/browse11/1-m/en

https://wearesocial.com/digital-2020.

Kartol, A., \& Peker, A. (2020). Ergenlerde sosyal ortamlarda gelişmeleri kaçırma korkusu (fomo) yordayıcılarının incelenmesi. Opus Uluslararası Toplum Araştırmalar Dergisi, 15(21), 454-474.

King, A. L. S., Valença, A. M., \& Nardi, A. E. (2010). Nomophobia: the mobile phone in panic disorder with agoraphobia: reducing phobias or worsening of dependence?. Cognitive and Behavioral neurology, 23(1), 52-54.

King, A. L. S., Valenca, A. M., Silva, A. C. O., Baczynski, T., Carvalho, M. R., \& Nardi, A. E. (2013). Nomophobia: Dependency on virtual environments or social phobia?. Computers in Human Behavior, 29(1), 140-144.

Leary, M. R., Twenge, J. M., \& Quinlivan, E. (2006). Interpersonal rejection as a determinant of anger and aggression. Personality and social psychology review, 10(2), 111132.

Lee, E. J., \& Cho, E. (2018). When using Facebook to avoid isolation reduces perceived social support. Cyberpsychology, Behavior, and Social Networking, 21(1), 32-39. doi: 10.1089/cyber.2016.0602. Epub 2017 Jun 26. PMID: 28650208.

Li, L., Griffiths, M. D., Niu, Z., \& Mei, S. (2020). Fear of missing out (FoMO) and gaming disorder among Chinese university students: Impulsivity and game time as mediators. Issues in Mental Health Nursing, 41(12), 1104-1113.
Milyavskaya, M., Saffran, M., Hope, N., \& Koestner, R. (2018). Fear of missing out: prevalence, dynamics, and consequences of experiencing FOMO. Motivation and Emotion, 42(5), 725-737.

Orhan Göksun, D. (2019). Gelişmeleri Kaçırma Korkusu ve Problemli İnternet Kullanımı Arasındaki İlişki. Mersin University Journal Of The Faculty Of Education, 15(2), 511-525.

Ostovar, S., Bagheri, R., Griffiths, M. D., ve Mohd Hashima, I. H. (2021). Internet Addiction and Maladaptive Schemas: The Potential Role of Disconnection/Rejection and Impaired Autonomy/Achievement. Clinical Psychology \& Psychotherapy. https://doi.org/10.1002/cpp.2581

Przybylski, A. K., Murayama, K., DeHaan, C. R., \& Gladwell, V. (2013). Motivational, emotional, and behavioral correlates of fear of missing out. Computers in human behavior, 29(4), 1841-1848.

Reer, F., Tang, W. Y., \& Quandt, T. (2019). Psychosocial wellbeing and social media engagement: The mediating roles of social comparison orientation and fear of missing out. New Media \& Society, 21(7), 1486-1505.

Riordan, B. C., Flett, J. A., Hunter, J. A., Scarf, D., \& Conner, T. S. (2015). Fear of missing out (FoMO): The relationship between FoMO, alcohol use, and alcohol-related consequences in college students. Annals of Neuroscience and Psychology, 2(7), 1-7.

Rozgonjuk, D., Elhai, J. D., Ryan, T., \& Scott, G. G. (2019). Fear of missing out is associated with disrupted activities from receiving smartphone notifications and surface learning in college students. Computers \& Education, 140, 103590

Rozgonjuk, D., Sindermann, C., Elhai, J. D., \& Montag, C. (2020). Fear of Missing Out (FoMO) and social media's impact on daily-life and productivity at work: Do WhatsApp, Facebook, Instagram, and Snapchat Use Disorders mediate that association?. Addictive Behaviors, 110, 106487. doi: 10.1016/j.addbeh.2020.106487. Epub 2020 May 27. PMID: 32674020 .

Sela, Y., Zach, M., Amichay-Hamburger, Y., Mishali, M., \& Omer, H. (2020). Family environment and problematic internet use among adolescents: the mediating roles of depression and fear of missing out. Computers in Human Behavior, 106, 106226. https://doi.org/10.1016/j.chb.2019.106226.

Véronneau, M. H., Koestner, R. F., \& Abela, J. R. (2005). Intrinsic need satisfaction and well-being in children and adolescents: An application of the self-determination theory. Journal of Social and Clinical Psychology, 24(2), 280-292.

Wolniewicz, C. A., Rozgonjuk, D., \& Elhai, J. D. (2020). Boredom proneness and fear of missing out mediate relations between depression and anxiety with problematic smartphone use. Human Behavior and Emerging Technologies, 2(1), 61-70.

Yıldız, K., Kurnaz, D., \& Kırık, A. M. (2020). Nomofobi, netlessfobi ve gelişmeleri kaçırma korkusu: Sporcu genç yetişkinler üzerine bir araștırma. Manisa Celal Bayar Üniversitesi Sosyal Bilimler Dergisi, 18(Özel Say1), 321-338.

Yıldız, H., \& Yıldız, B. (2016). Sanal kaytarma yapmak kötü bir şey değildir. Ama. Harvard Business Review Türkiye, Eylül, 108115 .

Young, K. S. (2011). CBT-IA: The first treatment model for internet addiction. Journal of Cognitive Psychotherapy, 25(4), $304-312$. 